\title{
Divalent Europium Doped and Un-doped Calcium Iodide Scintillators: Scintillator Characterization and Single Crystal Growth
}

\author{
L. A. Boatner ${ }^{1,2}$, J. O. Ramey ${ }^{1,2}$, J. A. Kolopus ${ }^{1,2}$, and John S. Neal ${ }^{1,3}$ \\ ${ }^{1}$ Center for Radiation Detection Materials \& Systems \\ ${ }^{2}$ Materials Science and Technology Division \\ ${ }^{3}$ Nuclear Science and Isotope Technology Division \\ Oak Ridge National Laboratory, Oak Ridge, Tennessee 37831
}

a author to whom Correspondence should be addressed

${ }^{a}$ L. A. Boatner

boatnerla@ornl.gov

Phone: 865-574-5492 FAX: 865-574-4814

1 Bethel Valley Road

Oak Ridge, TN 37831

Joanne O. Ramey

Oak Ridge National Laboratory

MS-6188, Bldg. 4500N

Oak Ridge, TN 37831 USA

rameyjo@ornl.gov

James A. Kolopus

Oak Ridge National Laboratory

MS-6044, Bldg. 3150

Oak Ridge, TN 37831 USA

kolopusja@ornl.gov

John S. Neal

Oak Ridge National Laboratory

MS-6010, Bldg. 3500

Oak Ridge, TN 37831 USA

nealjs1@ornl.gov

POTENTIAL REFEREES:

Dr. David Wehe dkw@umich.edu

Dr. Larry Franks franksla@nv.doe.gov

Dr. Dale L. Perry DLPerry@lbl.gov 


\title{
Divalent Europium-doped and Un-doped Calcium Iodide Scintillators: Scintillator Characterization and Single Crystal Growth
}

\author{
L. A. Boatner ${ }^{1,2}$, J. O. Ramey ${ }^{1,2}$, J. A. Kolopus ${ }^{1,2}$, and John S. Neal ${ }^{1,3}$ \\ ${ }^{1}$ Center for Radiation Detection Materials \& Systems \\ ${ }^{2}$ Materials Science and Technology Division \\ ${ }^{3}$ Nuclear Science and Isotope Technology Division \\ Oak Ridge National Laboratory, Oak Ridge, Tennessee 37831
}

\begin{abstract}
The alkaline-earth scintillator, $\mathrm{CaI}_{2}: \mathrm{Eu}^{2+}$, was initially discovered around 1964 by Hofstadter, Odell, and Schmidt. Serious practical problems quickly arose, however, that were associated with the growth of large monolithic single crystals of this material due to its lamellar, mica-like structure. As a result of its theoretically higher light yield, $\mathrm{CaI}_{2}: \mathrm{Eu}^{2+}$ has the potential to exceed the excellent scintillation performance of $\mathrm{SrI}_{2}: \mathrm{Eu}^{2+}$. In fact, theoretical predictions for the light yield of $\mathrm{CaI}_{2}: \mathrm{Eu}^{2+}$ scintillators suggested that an energy resolution approaching $2 \%$ at $662 \mathrm{keV}$ could be achievable. As in the case of the early $\mathrm{SrI}_{2}: \mathrm{Eu}^{2+}$ scintillator, the performance of $\mathrm{CaI}_{2}: \mathrm{Eu}^{2+}$ scintillators has traditionally suffered due, at least in part, to outdated materials synthesis, component stoichiometry/purity, and single-crystal-growth techniques. Based on our recent work on $\mathrm{SrI}_{2}: \mathrm{Eu}^{2+}$ scintillators in single-crystal form, we have developed new techniques that are applied here to $\mathrm{CaI}_{2}: \mathrm{Eu}^{2+}$ and pure $\mathrm{CaI}_{2}$ with the goal of growing large uncracked crystals and, potentially, realizing the theoretically predicted performance of the $\mathrm{CaI}_{2}: \mathrm{Eu}^{2+}$ form of this material. Calcium iodide does not adhere to modern glassy carbon Bridgman crucibles - so there should be no differential thermal-contraction-induced crystal/crucible stresses on cooling that would result in crystal cracking of the lamellar structure of $\mathrm{CaI}_{2}$. Here we apply glassy carbon crucible Bridgman growth, high-purity growthcharge compounds, our molten salt processing/filtration technique, and extended vacuum-meltpumping methods to the growth of both $\mathrm{CaI}_{2}: \mathrm{Eu}^{2+}$ and un-doped $\mathrm{CaI}_{2}$. Large scintillating single crystals were obtained, and detailed characterization studies of the scintillation properties of $\mathrm{CaI}_{2}: \mathrm{Eu}^{2+}$ and pure $\mathrm{CaI}_{2}$ single crystals are presented that include studies of the effects of plastic deformation of the crystals on the scintillator performance.
\end{abstract}


Key Words: Scintillator Crystal growth Bridgman growth $\mathrm{CaI}_{2}: \mathrm{Eu}$ Plastic deformation

\section{Introduction}

The divalent-europium-doped alkaline-earth halide scintillator, $\mathrm{CaI}_{2}: \mathrm{Eu}^{2+}$, was initially reported by Hofstadter, Odell, and Schmidt in 1964 [1,2]. This scintillator was subsequently patented by Hofstadter in 1967 [3]. At that time, the material was reported to be a promising scintillator based on the light yield alone. Another alkaline-earthiodide scintillator, namely $\mathrm{SrI}_{2}: \mathrm{Eu}^{2+}$, was also discovered by Hofstadter and patented in 1968 [4], but the performance of the $\mathrm{SrI}_{2}: \mathrm{Eu}^{2+}$ scintillator at that time was not impressive in terms of its light yield and energy resolution, and no significant further development of this detector took place for decades. The $\mathrm{SrI}_{2}: \mathrm{Eu}^{2+}$ scintillator was essentially rediscovered in 2008 [5,6], and as reported in Refs. [5] and [6], outstanding energy resolution and light yields of the material were achieved through the application of significantly improved modern purification and synthesis methods, the use of increased Eu-activator doping levels, and modern crystal-growth techniques [7,8]. These more recent findings have resulted in a plethora of new research efforts leading to the continuing development, refinement, and current commercialization of the (now) highresolution $\mathrm{SrI}_{2}: \mathrm{Eu}^{2+}$ scintillator.

In principle, $\mathrm{CaI}_{2}: \mathrm{Eu}^{2+}$ has the potential to exceed the excellent scintillation performance of $\mathrm{SrI}_{2}: \mathrm{Eu}^{2+}$ due to its reported theoretically predicted higher light yield (114,000 photons/MeV [theoretical]) [5]. Unlike the case of recent work on $\operatorname{SrI}_{2}: \mathrm{Eu}^{2+}$, however, further developmental studies of $\mathrm{CaI}_{2}: \mathrm{Eu}^{2+}$ have not been extensively pursued, and therefore, its performance has not been improved - apparently due primarily to observations in both the early and recent literature regarding the lamellar micaceous-like 
crystal structure of this material and the associated formation of "layered" single crystals that exhibit mechanical instability (e.g. cracking and cleavage) problems - both during crystal growth and subsequent detector fabrication. Accordingly, the primary goal of present work was to apply high-purity compounds, modern crystal-growth methods, and non-reactive crucible materials to address the issue of the scintillator performance that could, in fact, be achieved with $\mathrm{CaI}_{2}: \mathrm{Eu}^{2+}$ Bridgman-grown scintillator crystals. Additionally, since un-doped $\mathrm{CaI}_{2}$ is also a scintillator, pure $\mathrm{CaI}_{2}$ scintillator single crystals were also grown using the same methods applied to the growth of Eu-doped $\mathrm{CaI}_{2}$, and their scintillator performance properties were investigated. A major premise on which these studies were based was that mechanical deformation of the scintillator crystals due to adherence to the growth crucible (or other mechanical interactions) would severely degrade the scintillator light yield and energy resolution - or potentially even suppress the scintillation mechanism completely. The results reported here show that, in fact, this premise did not prove to be well founded.

As noted, one goal of this work was to move toward a realization of the predicted theoretical high-resolution scintillator performance of $\mathrm{CaI}_{2}: \mathrm{Eu}^{2+}$ Accordingly, in addition to the use of high-purity crystal-growth-charge materials and the ORNLdeveloped molten salt filtration process $[7,8]$ for the removal of insoluble oxy-halides and other insoluble compounds from the melt prior to Bridgman growth, this work proceeded along two additional major promising research and development paths. These were: first, the use of vitreous carbon Bridgman crucibles for the growth of $\mathrm{CaI}_{2}$ and, second, the application of an extended vacuum/melt pumping procedure [8] prior to the encapsulation 
of the glassy carbon Bridgman crucible in a sealed quartz ampoule under 0.5 atm of Argon.

The availability of the large single crystals of both $\mathrm{CaI}_{2}: \mathrm{Eu}^{2+}$ and un-doped $\mathrm{CaI}_{2}$ that were produced during the course of this work also provided an opportunity for investigations of the effects of deliberate/intentional mechanical deformation (specifically plastic deformation) on the scintillator performance of $\mathrm{CaI}_{2}: \mathrm{Eu}^{2+}$ and un-doped $\mathrm{CaI}_{2}$. These plastic deformation experiments yielded performance results that were both unanticipated and intriguing in the sense that they ran counter to traditional/intuitive expectations of the effects of mechanical deformation on the single-crystal scintillator light yield and energy resolution.

\section{Experimental}

\subsection{The use of high-purity materials for the growth of $\mathrm{CaI}_{2}: \mathrm{Eu}^{2+}$ and un-doped $\mathrm{CaI}_{2}$}

Starting crystal-growth-charge materials (specifically the $\mathrm{CaI}_{2}$ host material) are currently commercially available whose purity exceeds that of the $\mathrm{CaI}_{2}$ compounds generally available during the 1960's-era period of Hofstadter's initial discovery of the $\mathrm{CaI}_{2}: \mathrm{Eu}^{2}$ scintillator [1,2]. Accordingly, in the crystal growth experiments described here, anhydrous -10 mesh $\mathrm{CaI}_{2}$ beads of $99.999 \%$ purity (with respect to metals) were used that were obtained from SAFC Hitech (Sigma Aldrich Co., LLC). It is important to note that the traditional chemical analysis supplied by the compound vendor does not, however, address issues of the stoichiometry of the material. The EuI 2 activator dopant was also obtained from SAFC Hitech with a stated purity of 99.99\%. This level of purity/stoichiometry was found to be generally unsatisfactory for the growth of highquality $\mathrm{CaI}_{2} \mathrm{Eu}^{2+}$ single-crystals, and therefore, further purification of the $\mathrm{EuI}_{2}$ material 
was carried out via zone refining by the research group of Arnold Burger at Fisk University, Nashville, TN. In our experience, this additional step of the purification of $\mathrm{EuI}_{2}$ is critical. The mixed $\mathrm{CaI}_{2} / \mathrm{EuI}_{2}$ (or pure $\mathrm{CaI}_{2}$ in the case of un-doped crystal growth) materials were dried in the growth ampoule system described in detail below by heating under vacuum in a system that utilized a liquid nitrogen cold trap to remove condensable vapors.

\subsection{Bridgman growth of $\mathrm{CaI}_{2}: \mathrm{Eu}^{2+}$ and un-doped $\mathrm{CaI}_{2}$ in vitreous carbon crucibles}

The crystallographic structural basis for the mechanical fragility and tendency for cleaving or cracking of $\mathrm{CaI}_{2}$ is illustrated in Fig. 1 along with the basic structural data for this material (Rhombohedral, hP3; Space group P-3m1, No 164, octahedral coordination). This figure clearly shows the planar micaceous-like structure created by continuous twodimensional sheets of polyhedra that form the $\mathrm{CaI}_{2} \mathrm{a}-\mathrm{b}$ plane. These structural sheets are separated along the c-axis direction by a distance of 3.487 angstroms. This structure results in an easy a-b basal-plane cleavage and is in contrast to the crystal structure of orthorhombic $\mathrm{SrI}_{2}$ - as illustrated in Figure 1 of Ref. [7] - i.e., a continuous $\mathrm{SrI}_{2}$ crystal structure is formed by 3-dimensionally linked polyhedral chains, and there are no clearly defined cleavage planes in this case.

As noted above, we have investigated the application of the advanced, modern crystal growth crucible material, namely vitreous (or glassy) carbon, to the Bridgman growth of Eu-activated and pure $\mathrm{CaI}_{2}$. Solid calcium iodide does not adhere to glassy carbon. The original premise behind this approach was that by eliminating crystal/crucible interactions one could eliminate adherence of the crystal to the crucible and the associated stress-induced cracking on cooling (due to differential thermal 
contraction). Accordingly, in the absence of other perturbations, it should be possible, to grow large un-fractured single crystals of pure or Eu-doped calcium iodide. High-quality glassy carbon (Sigradur GCG125) Bridgman growth crucibles with a volume of $125 \mathrm{ml}$ were obtained from Hochtemperatur-Werkstoffe GmbH in Thierhaupten, Germany and used in the experiments described here.

The application of vitreous carbon Bridgman crucibles to the growth of pure and doped $\mathrm{CaI}_{2}$ was used in conjunction with the ORNL-pioneered method of physically filtering the molten salt of the material to be grown using quartz frit filters to remove oxy-halide or other particles that are insoluble in the melt itself [7,8], i.e., to eliminate precipitated particles of phases that would otherwise be present in the as-grown single crystals. In the absence of the application of this technique, such inclusions can provide sources of crack formation/nucleation and, thereby, adversely affect the mechanical robustness of the scintillator crystal. This molten-salt filtration method had not been applied previously to the growth of pure $\mathrm{CaI}_{2}$ or $\mathrm{CaI}_{2}: \mathrm{Eu}^{2+}$.

\subsection{Molten salt filtration combined with a vitreous carbon crucible}

The implementation of the molten salt filtration process in conjunction with the use of a vitreous carbon Bridgman crucible required the design and fabrication of the dual-function quartz apparatus illustrated in Figs. $2 a$ and $b$. $\{$ A prior abbreviated and preliminary description of this apparatus and its application was presented [8] at the SPIE Conference on Hard X-ray, Gamma Ray, and Neutron Detector Physics, San Diego, California, August 17-21 (2014)\}. The smaller quartz tube at the top of Fig. $2 a$ is used to couple the quartz assembly to a vacuum system equipped with a liquid nitrogen cold trap. The growth-charge material is initially 
placed in the larger quartz chamber shown in the upper half of the illustration where the white porous quartz frit filter can be seen at the bottom of this chamber. The entire assembly is placed in a vertical tube furnace with both the upper large chamber that initially contains the growth charge and the lower chamber that contains the glassy carbon crucible in the furnace hot zone. The growth charge material (either pure $\mathrm{CaI}_{2}$ or zone-refined Eu-doped $\mathrm{CaI}_{2}$ ) is then dried under vacuum by heating at $\sim 250^{\circ} \mathrm{C}$ for approximately $18 \mathrm{~h}$. At this point, the temperature in the tube furnace is increased above the melting point of $\mathrm{CaI}_{2}\left(779^{\circ} \mathrm{C}\right)$, and the melt is gravity fed to filter it though the porous quartz frit filter. The portion of the quartz assembly below the white frit filter in Fig, $2 a$ and connecting the upper larger chamber to the lower chamber that contains the glassy carbon Bridgman crucible forms an effective funnel - so that the molten-salt filtrate flows through a connecting narrow tube into the glassy carbon crucible. The details of this quartz structure are shown in Fig. $2 b$.

The ampoule at this point, the entire quartz assembly was backfilled with a half atmosphere of ultra-high-purity argon gas, and the preparation furnace was cooled to room temperature. This argon gas backfill was necessary to avoid deleterious volatility effects that otherwise were found to occur during the crystal-growth process. In the final preparation steps, the narrow "connecting" quartz tube shown in Figs. 2a,b was used to "seal off" (under the 0.5 atmosphere of Ar) the ampoule incorporating the vitreous carbon Bridgman crucible that, at this point, contained the filtered (or both filtered and vacuumpumped) growth charge. Finally, a solid quartz rod that was used to lower the ampoule through the vertical Bridgman crystal growth furnace was fused to the top of the sealed 
ampoule using a hydrogen/oxygen torch. The ampoule was then placed in the vertical Bridgman growth tube furnace where the hot-zone temperature was raised to $\mathrm{T}=850^{\circ} \mathrm{C}$, and the crystal growth rate was set at $\sim 0.5 \mathrm{~mm} / \mathrm{h}$. Examples of Bridgman-grown crystals that were grown as described above (and described subsequently in the case of the use of an extended vacuum-melt-pumping growth-charge preparation technique) are shown in Fig. 3.

It should be noted as a cautionary point that numerous single crystals of a wide range of halides (and alkaline-earth iodides in particular) have been grown during the course of our research on scintillator materials. Of all of these materials, calcium iodide was found to be the most hygroscopic and air sensitive. Accordingly, protocols were utilized for the loading of the "inert-atmosphere-sealed," as-received from the vendor $\mathrm{CaI}_{2}$ into the quartz preparation assembly shown in Figs. 2a,b completely inside the dry box. Additionally, the ensuing transfer of the $\mathrm{CaI}_{2}$-loaded quartz assembly to the preparation furnace avoided any and all contact of the $\mathrm{CaI}_{2}$ growth charge with the air. Subsequent to the growth of the crystals, all preparation steps, (e.g., crystal cutting/cleaving, loading onto the photomultiplier tube for characterization studies, etc.) were carried out inside the dry atmosphere of the glove box. The precautions for avoiding contact of the crystals with the air included the use of a vacuum tight aluminum chamber equipped with an "O" ring that enabled the evacuated chamber to be sealed onto and held in place on the face of the PMT by atmospheric pressure - utilizing a principle somewhat similar to that used for the device described in Ref. [9].

In some of the later and most recent growth experiments, and based on the results of the $\mathrm{SrI}_{2}: \mathrm{Eu}^{2+}$ crystal-growth experiments described in Ref. [8], the protocol of vacuum 
pumping on the molten growth charge for 24 to 48 hours was employed in combination with the molten salt filtration technique described above. This procedure had previously been found [8] to be effective in significantly reducing the cracking on cooling of single crystals of Bridgman-grown $\mathrm{SrI}_{2}: \mathrm{Eu}^{2+}$.

\section{Scintillator Characterization Results}

\subsection{Luminescence spectra of $\mathrm{CaI}_{2}: \mathrm{Eu}^{2+}$ and un-doped $\mathrm{CaI}_{2}$}

The X-ray-excited luminescence spectrum of a single crystal of pure $\mathrm{CaI}_{2}$ is shown in Fig. 4 along with the X-ray-excited spectrum of a 5\% Eu-doped $\mathrm{CaI}_{2}$ and a 3\% Eu-doped $\mathrm{CaI}_{2}$ sample. As evident in Fig. 4, the luminescence line width of the pure $\mathrm{CaI}_{2}$ crystal is significantly broader than that of the two Eu-doped $\mathrm{CaI}_{2}$ samples. The luminescence for the un-doped $\mathrm{CaI}_{2}$ sample peaks around $400 \mathrm{~nm}$. Although there are slight variations in the peak positions of the Eu-doped samples that were observed in the concentration range of 3 to $10 \%$ Eu (with the largest shift observed for a 10\% Eu-doped crystal), the luminescence maximum generally occurs in the vicinity of $\sim 475 \mathrm{~nm}$ as indicated in Fig. 4. The $475 \mathrm{~nm}$ emission wavelength is sufficiently long to be compatible with the use of Si photodiode detectors rather than PMT'S. Figure 5 shows the effective magnitude of the Eu doping-concentration-dependent shifts in the emission peak in a more detailed view of the X-ray-excited $(150 \mathrm{kVp})$ spectra for the $3 \%$ and $5 \%$ Eu-doped $\mathrm{CaI}_{2}$ crystals - with the broader "tail" of the pure $\mathrm{CaI}_{2}$ spectrum superimposed and overlapping somewhat in the spectral region of the Eu-activated samples.

\subsection{Pulse height spectra for $\mathrm{CaI}_{2}: \mathrm{Eu}^{2+}$ and un-doped $\mathrm{CaI}_{2}$}

The pulse height spectrum for a 3\%Eu-doped $\mathrm{CaI}_{2}$ crystal is shown in Fig. 6 for the case of excitation by $662 \mathrm{keV}$ gamma rays from ${ }^{137} \mathrm{Cs}$. The spectrum for a $662 \mathrm{keV}$ 
gamma-ray-excited bismuth germanate scintillator is also shown for comparison purposes. The light yield for this $\mathrm{CaI}_{2}-\mathrm{Eu}$ scintillator was determined to be 47,800 photons $/ \mathrm{MeV}$ (corrected for the PMT response), and the FWHM of the $\mathrm{CaI}_{2}: \mathrm{Eu}^{2+}$ photopeak yields a value of $8.9 \%$ for the energy resolution. The width of the photopeak observed for the Eudoped $\mathrm{CaI}_{2}$ crystals was found to generally increase with increasing Eu-activator concentration, and for the higher Eu concentrations, it also frequently exhibited an unusual "multi-peak" structure .

During the ongoing course of the experiments on the growth and characterization of $\mathrm{CaI}_{2}$-based scintillators described here, the beneficial effects of crystal crack elimination/reduction by extended vacuum pumping on the molten salt of $\mathrm{SrI}_{2}: \mathrm{Eu}^{2+}$ were discovered. As described in Ref. [8] and as illustrated in Fig. 1 of that reference, very serious and pervasive problems associated with the cracking of single crystals of $\operatorname{SrI}_{2}: \mathrm{Eu}^{2+}$ during, and sometimes after the solidification growth process, were significantly ameliorated (See the bottom photograph in Fig. 1 of Ref. [8]) by applying a growth-charge preparation protocol that consisted of an extended (up to $48 \mathrm{~h}$ ) vacuum pumping step applied to the molten $\mathrm{SrI}_{2}: \mathrm{Eu}^{2+}$ salt - i.e., applied subsequent to the moltensalt quartz-frit filtration treatment [7]. Accordingly, this extended vacuum melt pumping technique was also applied to the pre-growth preparation of $\mathrm{CaI}_{2}: \mathrm{Eu}^{2+}$. Figure 7 shows a comparison of the pulse height spectrum for an un-melt-pumped $\mathrm{CaI}_{2}: \mathrm{Eu}^{2+}(3 \% \mathrm{Eu})$ Bridgman-grown crystal with that of a $\mathrm{CaI}_{2}: \mathrm{Eu}^{2+}(3 \% \mathrm{Eu})$ crystal where the $48 \mathrm{~h}$ melt pumping protocol had been used. The light yield of the melt-pumped sample has clearly decreased along with its energy resolution relative to the un-pumped $\mathrm{CaI}_{2}: \mathrm{Eu}^{2+}$ specimen. An examination of the material captured in the liquid nitrogen cold tap during the 
extended vacuum-melt-pumping operation revealed that some of the Eu activator dopant had been lost during the $48 \mathrm{~h}$ duration melt-pumping step of Eu-doped $\mathrm{CaI}_{2}$ - indicating that this loss of activator was responsible for the observed corresponding decrease in the scintillation light yield and energy resolution evident in Fig. 7. Such a loss of the Eu activator had not previously been observed in the case of the 48 hour-long melt pumping of $\mathrm{SrI}_{2}: \mathrm{Eu}^{2+}$. This difference in behavior is attributed to volatility/decomposition effects that are associated with the higher melting point of $\mathrm{CaI}_{2}\left(779^{\circ} \mathrm{C}\right)$ versus the significantly lower melting point of $\operatorname{SrI}_{2}\left(515{ }^{\circ} \mathrm{C}\right)$. These effects became evident during a $48 \mathrm{~h}$-long vacuum-melt-pumping period for the higher-melting-point $\mathrm{CaI}_{2}$ compound.

The issue of Eu-activator loss and decreased scintillator performance during the extended vacuum-melt-pumping of $\mathrm{CaI}_{2}$ was addressed in the following manner: First, the growth charge preparation described in Section 2.3 above was initially applied only to pure un-doped $\mathrm{CaI}_{2}$ - i.e., the pure compound was placed in the upper chamber of the quartz assembly illustrated in Fig. 2, dried by heating under vacuum, melted, and then filtered through the quartz frit into the glassy carbon Bridgman crucible. The filtered un-doped $\mathrm{CaI}_{2}$ charge was kept in the molten state, and the extended vacuum-melt-pumping process was performed for $24 \mathrm{~h}$. (It is important to note that the temperature of the portion of the assembly shown in Fig. 2 that contains the quartz frit filter should be maintained above the melting point of $\mathrm{CaI}$ during the entire meltpumping process. Otherwise, the $\mathrm{CaI}_{2}$ that is entrained in the porosity of the frit filter solidifies and blocks the filter - so the vacuum-pumping process is only carried out on the clogged filter and not on the melt itself.) At this point, the quartz envelope containing the $\mathrm{CaI}_{2}$-filled glassy carbon crucible was sealed under $0.5 \mathrm{~atm}$ of pure $\mathrm{Ar}$, and the 
system was cooled to room temperature, and A rapid directional-solidification Bridgman pass was then carried out. The resulting purified un-doped $\mathrm{CaI}_{2}$ material was removed and re-loaded into the assembly shown in Fig. 2 - along with the desired doping level of zone-refined $\mathrm{EuI}_{2}$. This $\mathrm{EuI}_{2}$-doped charge was then melted, frit-filtered into the vitreous carbon crucible, and sealed in the quartz envelope under $0.5 \mathrm{~atm}$ of high-purity Ar. The vacuum melt pumping procedure was $\underline{\text { not }}$ carried out on the Eu doped $\mathrm{CaI}_{2}$ at this point to avoid the loss of Eu activator as previously discussed. The Eu-doped $\mathrm{CaI}_{2}$ material was then used in carrying out a final Bridgman growth pass at a slow solidification rate of $\sim 0.25 \mathrm{~mm} / \mathrm{h}$. A comparison of the pulse height spectra for a $3 \%$ Eu-doped $\mathrm{CaI}^{2}$ crystal grown as described above with that of a $\mathrm{CaI}_{2}: \mathrm{Eu}^{2+}(3 \% \mathrm{Eu})$ crystal that was grown using frit filtration and a vitreous carbon crucible - but without the use of any melt pumping procedure initially applied to pure $\mathrm{CaI}_{2}$ prior to Eu doping is shown in Fig. 8. In this case, the light yield using $662 \mathrm{keV}$ gamma-ray excitation has increased to a value of 54,900 photons $/ \mathrm{MeV}$ relative to the light yield of 50,800 photons $/ \mathrm{MeV}$ for the material that was not vacuum-melt-pumped using the two-step process described above.

Figure 9 illustrates the pulse height spectrum obtained for an un-doped Bridgmangrown single crystal of $\mathrm{CaI}_{2}$ acquired using $662 \mathrm{keV}{ }^{137} \mathrm{Cs}$ gamma-ray excitation. The light yield of this crystal was determined to be 39,800 photons/MeV (corrected for the PMT response), but as shown in the figure, the photopeak was quite broad, and accordingly, the energy resolution was poor. A pulse height spectrum of bismuth germanate obtained using $662 \mathrm{keV}$ excitation is also shown in Fig. 9 for comparison purposes.

\section{Characterization Results for Plastically Deformed $\mathrm{CaI}_{2}: \mathrm{Eu}^{2+}$ Scintillators}


One physical manifestation of the lamellar, micaceous crystal structure of $\mathrm{CaI}_{2}$, as shown in Fig. 1, is the ability to plastically deform the crystals. As previously noted, a major premise of the current work was that mechanical deformation of the $\mathrm{CaI}_{2}$ due to crystal-crucible interactions (i.e., adherence of the crystal to a quartz Bridgman crucible coupled with differential thermal contraction) would adversely affect the scintillator performance. The ability to plastically deform $\mathrm{CaI}_{2}$ crystals provided an effective means of testing this premise - i.e., the assumption being that deliberate plastic deformation would result in a significant degradation of the scintillator light yield and energy resolution - or possibly even destroy the ability of the material to scintillate. Accordingly, in carrying out these deformation experiments, a flat single-crystal plate of $\mathrm{CaI}_{2}: 5 \% \mathrm{Eu}$ was plastically deformed in the glove box by bending the material around a $\sim 5.0 \mathrm{~cm}$-diameter round mandrel. The sample was then re-straightened by pressing on a flat plate. The pulse height spectra for the original un-deformed crystal and the bent and then re-straightened scintillator are illustrated in Fig. 10. As shown in this figure, the act of plastically deforming and then re-straightening the crystal has, in fact, improved the scintillation properties - the original photo-peak for the un-deformed crystal that was broad and exhibited the multi-peak structure noted previously was replaced in the deformed/straightened crystal by an essentially single and narrower (i.e., a higher resolution) peak located at channel numbers corresponding to an increased light yield.

This unexpected result shows that the initial "premise" that highly deleterious effects would arise from the mechanical deformation of $\mathrm{CaI}_{2}$ was ill founded. Due to the unanticipated nature of this result, a number of subsequent plastic deformation "bending" and re-straightening experiments were carried out using cleaved flat plates of $\mathrm{CaI}_{2}: \mathrm{Eu}^{2+}$ 
crystals. The results for a series of three consecutive bends followed each time by the straightening of a $\mathrm{CaI}_{2}: \mathrm{Eu}^{2+}$ Bridgman-grown crystal are shown in Fig. 11. (In obtaining the pulse height data between the successive bending and re-straightening operations, a template was cut corresponding to the outline of the crystal and adhered to the face of the PMT. This approach ensured that the scintillator crystal was placed in the same position on the PMT relative to the tube cathode each time.) As evident in this figure, each consecutive bend and straightening resulted in the "high-channel-number" edge of the photo peak shifting to an increased light-yield position. Accordingly, this effect evidently represents a generally reproducible phenomenon that runs contrary to traditional expectations. In a few cases, where the multiple-photo peak exhibits structure that consists of a number of small peaks that are relatively widely separated, bending and re-straightening the crystal results in a replacement of the multiple peaks with one photopeak whose position is only slightly shifted but whose width is noticeably increased.

The X-ray-excited luminescence spectra of both an un-bent crystal $\mathrm{CaI}_{2}: \mathrm{Eu}^{2+}$ crystal and the same crystal that was bent and re-straightened three times (see Fig. 11) are illustrated in Fig. 12. These results show that only relatively minor changes in the luminescence spectrum result from plastic deformation of the sample - while significant changes are observed in the ${ }^{137} \mathrm{Cs} 662 \mathrm{keV}$ gamma-ray-excited pulse-height spectra.

A bending and re-straightening experiment was also carried out using a pure undoped single crystal of $\mathrm{CaI}_{2}$, and the results of this experiment using $662 \mathrm{keV}{ }^{137} \mathrm{Cs}$ gamma ray excitation are illustrated in Fig. 13. In this case, the relatively broad photopeak does, in fact, broaden even further and shifts to lower channel numbers - i.e., the behavior following deformation of the un-doped $\mathrm{CaI}_{2}$ crystal is opposite to the 
unanticipated behavior observed for the Eu-activated scintillator. The implications of these deformation results for energy transfer effects and mechanisms in the over-all scintillation process merit further consideration.

\section{Summary}

In his 1967 U.S. Patent on Eu-activated $\mathrm{CaI}_{2}$ scintillators [3] and the associated publication [1], Hofstadter originally pointed out the disadvantages of this material - i.e., its higher hygroscopic (actually deliquescent) nature relative to NaI, a lack of machinability, and its basal-plane cleavage (See Fig.1) that makes it both susceptible to thermal shock and difficult to cut perpendicular to the basal plane. However, Hofstadter also noted some advantages of $\mathrm{CaI}_{2}: \mathrm{Eu}^{2+}$ relative to $\mathrm{NaI}(\mathrm{Tl})$ - namely, a superior light yield at $662 \mathrm{keV}$ of $190 \%$ as measured relative to a $\mathrm{NaI}(\mathrm{Tl})$ scintillator and an associated higher energy resolution of $6.0 \%$. More recently, a theoretical prediction of the light yield of $\mathrm{CaI}_{2}: \mathrm{Eu}^{2+}$ yielded a promising value of 114,000 photons/MeV [5]. Accordingly, based on our previous work on $\operatorname{SrI}_{2}: \mathrm{Eu}^{2+}$, a scintillator that was also originally patented by Hofstadter [4], the goal of this effort was to apply modern crystal growth materials and methods to the growth of single crystals of both $\mathrm{CaI}_{2}: \mathrm{Eu}^{2+}$ and pure $\mathrm{CaI}_{2}$ with the objective of achieving improvements in the scintillator performance of $\mathrm{CaI}_{2}: \mathrm{Eu}^{2+}$ that would, first, be analogous to those improvements realized previously using similar approaches in the case of $\mathrm{SrI}_{2}: \mathrm{Eu}^{2+}$, and second, to attempt to achieve the scintillator light yield (114,000 photons/MeV) and corresponding energy resolution (e.g. 2\%), that had previously been theoretically predicted for $\mathrm{CaI}_{2}: \mathrm{Eu}^{2+}$ [5]. It should be noted that, in regard to this latter goal, the light yields achieved here and previously reported by 
Hofstadter fell significantly short of the predicted theoretical value, and these results call into question the accuracy of this calculated performance.

A variety of crystal-growth approaches and treatments, as described in the text of this article, were investigated in pursuing the goals noted above. The scintillator light yields achieved for $\mathrm{CaI}_{2}: \mathrm{Eu}^{2+}$ (and for un-doped $\mathrm{CaI}_{2}$ ) using a variety of Eu-activator concentrations are given in Table 1. Clearly, as noted above, none of these light yields approaches the reported theoretical value of 114,000 photons $/ \mathrm{MeV}$. There is a general increasing trend in the light yield with increasing Eu-activator concentration up to 6\% followed by a decrease in light yield when the Eu-content is further increased to $10 \%$. However, we have found that the photopeak broadens (i.e., structure in the form of multiple peaks appears) with increasing Eu content above 4-5\% - so that the energy resolution, in fact, decreases with increasing Eu-concentration above these dopant levels.

The technique of vacuum-melt-pumping described previously in Ref. 8 and that was successfully applied to reducing crystal cracking and generally improving the crystal quality of $\mathrm{SrI}_{2}: \mathrm{Eu}^{2+}$ was also applied here to the growth of $\mathrm{CaI}_{2}: \mathrm{Eu}^{2+}$. In the case of $\mathrm{CaI}_{2}: \mathrm{Eu}^{2+}$ growth, however, a two-stage method of growth charge preparation was developed that was necessary to reduce a significant loss of the Eu activator during the vacuum-melt-pumping process. This loss occurs at the melting point of $\mathrm{CaI}_{2}-$ which is significantly higher than that of $\mathrm{SrI}_{2}$. This two-stage vacuum-melt-pumping procedure resulted in the growth of the highest overall quality single crystals of $\mathrm{CaI}_{2}: \mathrm{Eu}^{2+}$ produced in the present work. 
As noted previously, vitreous carbon crucibles were used here for the growth of $\mathrm{CaI}_{2}: \mathrm{Eu}^{2+}$ based on the premise that the elimination of crystal-crucible interactions would avoid thermally induced mechanical stresses and improve the scintillator performance of the material. This hypothesis was thoroughly tested by utilizing the fact that $\mathrm{CaI}_{2}$ can be plastically deformed. Subsequent plastic deformation experiments showed that, in the case of $\mathrm{CaI}_{2}: \mathrm{Eu}^{2+}$ crystals, the scintillation properties actually improved after deliberate mechanical deformation - negating the original proposed concept.

One explanation for this unusual and un-anticipated behavior is potentially related to the lamellar/micaceous nature of the $\mathrm{CaI}_{2}$ structure shown in Fig. 1. Bending of the $\mathrm{CaI}_{2}$ crystals via deformation of the a-b plane results in relative slip of (i.e., between) the polyhedral-containing layered structural planes that are separated by 3.487 angstroms as indicated in Fig. 1. It is well established that defect-induced trapping centers and associated phenomena can significantly affect scintillation properties (See, for example Fig. 10 of Ref. [8]). Accordingly, in the present case, trapping centers that are associated with inter-layer structural defects or other types of trap-related defect centers, could be modified, eliminated, or significantly altered as a result of the significant displacements that occur between the polyhedral layers during bending of the $\mathrm{CaI}_{2} \mathrm{a}-\mathrm{b}$ plane. In the case of un-doped $\mathrm{CaI}_{2}$, however, it should be noted that plastic deformation did result in a slight decrease in the light yield and energy resolution.

$\mathrm{CaI}_{2}$ remains one of the most challenging and problematic materials in the family of alkaline-earth and alkali halide-based scintillators due to its extreme hygroscopic nature, softness and difficulty of fabrication - including cutting, polishing, etc., and its unusual behavior as a function of activator concentration. Nevertheless, the encouraging 
results obtained via the application of the two-stage vacuum-melt-pumping process developed here offer promise for future applications of this approach to the growth of other candidate scintillators in the alkaline-earth group of materials.

\section{Acknowledgements}

This research was sponsored in part by the Laboratory Directed Research and Development Program of Oak Ridge National Laboratory, managed by UT-Battelle for the U.S. Department of Energy and in part by the Nuclear Non-proliferation Program (NA-22) of the National Nuclear Security Administration, U.S. Department of Energy. Contributions by Alexandra E. Vandegrift and Jason Craig who fabricated the quartz growth-charge preparation apparatus described here are gratefully acknowledged as are the technical contributions of Shelby Stooksbury, the graphic-arts contributions of Sandra L. Salmen, and the preparation of the $\mathrm{CaI}_{2}$ crystal structure figure by Bryan Chakoumakos. The authors are indebted to Prof. Arnold Burger and the members of his research group at Fisk University in Nashville, Tennessee for carrying out the purification of $\mathrm{EuI}_{2}$ by zone refining. 
Table 1.

Table 1. $\mathrm{Cal}_{2}: \mathrm{Eu}^{2+}$ and Pure $\mathrm{CaI}_{2}$ Light Yield (LY)

\begin{tabular}{|c|c|}
\hline Eu Level & $\mathrm{LY}(\mathrm{ph} / \mathrm{MeV})$ \\
\hline $0 \%$ Un-doped & 39,800 \\
\hline $2 \%$ Vacuum melt pumped & 54,900 \\
\hline $3 \%$ & 50,800 \\
\hline $4 \%$ & 49,000 \\
\hline $5 \%$ & 57,900 \\
\hline $6 \%$ & 59,100 \\
\hline $7 \%$ & 40,500 \\
\hline
\end{tabular}




\section{References:}

[1] R. Hofstadter, E. W. Odell, and C. T. Schmidt, Review of Scientific Instruments 35 (1964) 246-247.

[2] R. Hofstadter, E. W. Odell, and C. T. Schmidt, IEEE Transactions on Nuclear Science 11 (1964) 12-14.

[3] R. Hofstadter, "Europium Activated Calcium Iodide Scintillators, US Patent $3,342,745$ (1967).

[4] R. Hofstadter, "Europium-activated Strontium Iodide Scintillators," US Patent 3,373,279 (1968).

[5] N. J. Cherepy, S. A. Payne, S. J. Asztalos, G. Hull, J. D. Kuntz, T. Niedermayr, S. Pimputkar, J. J. Roberts, R. D. Sanner, T. M. Tillotson, E. van Loef, C. M. Wilson, K. S. Shah, U. N. Roy, R. Hawrami, A. Burger, L. A. Boatner, W.-S. Choong, and W. W. Moses, IEEE Transactions on Nuclear Science 56 (2009) 873-880.

[6] Nerine J. Cherepy, Giulia Hull, Alexander D. Drobshoff, Stephen A. Payne, Edgar van Loef, Cody M. Wilson, Kanai Shah, Uptal N. Roy, Arnold Burger, Lynn A. Boatner, Woon-Seng Choong, and William W. Moses, Applied Physics Letters 92 (2008) 083508. 
[7] L. A. Boatner, J. O. Ramey, J. A. Kolopus, R. Hawrami, W. M. Higgins, E. van Loef, J. Glodo, K. S. Shah, Pijush Bhattacharya, Eugene, Tupitsyn, Michael Groza, Arnold Burger, N. J. Cherepy, and S. A. Payne, The Journal of Crystal Growth 379 (2013) 63-68.

[8] L. A. Boatner, J. O. Ramey, J. A. Kolopus, J. S. Neal, N. J. Cherepy, S. A. Payne, P. R. Beck, A. Burger, E. Rowe, and P. Bhattacharya, Proceedings of the SPIE 9213, Hard X-ray, Gamma-Ray, and Neutron Detector Physics XVI, Edited by Arnold Burger, Larry Franks, Ralph B. James, and Michael Fiederle, Proc. of the SPIE Vol. 9213 (2014) 92130J-1.

[9] Jane Y. Howe, Lynn A. Boatner, James A. Kolopus, Larry R. Walker, Chengdu Liang, Nancy J. Dudney, and Charles R. Schaich, Journal of Materials Science 47 (2012) 1572-1577. 


\section{Figure Captions:}

Fig. 1. Calcium iodide has a lamellar structure with the basal-plane layered "sheet-like" arrangement shown in the figure. This structural arrangement accounts for the ease with which single crystals of the material can be mechanically separated along the a-b plane into either thin sheets or slabs. The material is very soft, extremely hygroscopic, highly reactive, not readily amenable to either mechanical or solution polishing, and it can be easily plastically deformed via bending of the a-b plane.

Fig. 2a: Overall view of the quartz ampoule/vitreous carbon crucible assembly used for the growth of single crystals of $\mathrm{CaI}_{2}: \mathrm{Eu}^{2+}$ or pure $\mathrm{CaI}_{2}$. The growth charge material is initially placed in the large chamber above the white quartz frit filter. The assembly is placed in a vertical Bridgman furnace, evacuated, and heated for drying purposes. The dried growth charge is then melted, and the molten salt is filtered through the quartz frit. The liquid passes through the narrow tube connecting the large upper chamber to the lower growth chamber shown at the bottom of the apparatus and into the vitreous carbon Bridgman crucible. The quartz envelope growth chamber is then sealed at the narrow connecting tube under a 0.5 atmosphere of pure Ar gas and the quartz envelope is finally attached to a quartz rod for lowering through the vertical Bridgman furnace. Fig. 2b: Detailed view of the quartz ampoule/vitreous carbon crucible assembly showing the white quartz frit filter located in the lower end of the upper chamber of the apparatus. This chamber is connected by the "funnel-like" structure to the lower quartz chamber that holds the vitreous carbon Bridgman crucible. The intervening narrow tube extends all the way down to near the top of the crucible and is used to seal off the growth chamber under 0.5 atm of Argon. 
Fig. 3. Top: As-grown boule of $\mathrm{CaI}_{2}: \mathrm{Eu}^{2+}$ doped with $5 \% \mathrm{Eu}$ as removed from the vitreous carbon Bridgman crucible and photographed in the dry box. There was no evidence of adherence to the vitreous carbon, and the crystal simply slid out of the crucible without any resistance. Both the pure and Eu-doped $\mathrm{CaI}_{2}$ crystals, however, generally exhibit a very thin "frosted' surface below which the body of the material is transparent. This sample as frit filtered but not vacuum melt pumped.

Middle: Single crystal of $\mathrm{CaI}_{2}: \mathrm{Eu}^{2+}(2 \% \mathrm{Eu})$ grown using the two-stage process (described in detail in Section 3.2) in which pure $\mathrm{CaI}_{2}$ is first vacuum dried, frit filtered, vacuum melt pumped for $24 \mathrm{~h}$, and then subjected to a fast Bridgman growth pass. The resulting material is then doped with the desired level of Eu, re-melted, the molten salt is re-filtered, and the resulting material is finally subjected to a slow Bridgman growth pass. The ubiquitous thin frosted surface is still present except near the pointed end of the boule, but this method produces the highest optical quality scintillator material as shown in the bottom portion of this Figure.

Bottom: A slab of Eu-doped $\mathrm{CaI}_{2}(\sim 3 \mathrm{~mm}$ thick) is shown that was mechanically "sliced" from a single crystal boule using an Exacto (TM) knife blade. Due to the micaceous and very soft nature of $\mathrm{CaI}_{2}$, the samples can be easily "sliced" by hand from a bulk single crystal boule using a thin sharp blade to separate the layers of the material and achieve a desired thickness. Achieving a perfect atomic layer separation and a flat surface by this method is, however, generally problematic, since the layers tend to selectively stick together resulting in an uneven sample surface (much like the small region evident on the left-hand side of the slice shown in this bottom figure) - also the material is resistant to crystal "cleaving" in the traditional sense. Accordingly, the quality of the flat surface on the high-clarity, transparent $\mathrm{CaI}_{2}: \mathrm{Eu}^{2+}$ sample shown here that was grown by filtering and vacuum melt pumping of pure $\mathrm{CaI}_{2}$ followed by Eu doping (see Section 3.2 for details) is the exception rather than the rule.

Fig. 4. X-ray-excited luminescence spectra of pure $\mathrm{CaI}_{2}$ and $\mathrm{CaI}_{2}: \mathrm{Eu}^{2+}$ with two concentrations of Eu activator ions. The spectra were obtained using $150 \mathrm{kV}$-peak X-ray excitation. The emission from un-doped $\mathrm{CaI}_{2}$ is quite broad relative to that characteristic of Eu-activated $\mathrm{CaI}_{2}$, and it peaks very near $400 \mathrm{~nm}$ while the Eu-activated luminescence 
peaks around $475 \mathrm{~nm}$. A small shift in the peak of the emission wavelength is observed for $\mathrm{CaI}_{2}: \mathrm{Eu}^{2+}$ depending on the concentration of the Eu activator ion.

Fig. 5. The details of the X-ray-excited luminescence from $\mathrm{CaI}_{2}$ doped with varying levels of the divalent Eu activator ion are shown along with the longer wavelength "tail" of the luminescence from un-doped $\mathrm{CaI}_{2}$. The order-of magnitude of the variation observed in the $\mathrm{CaI}_{2}: \mathrm{Eu}^{2+} \mathrm{X}$-ray-excited luminesce peak is shown for two Eu-activator concentrations.

Fig. 6. Pulse height spectra are shown for a Bridgman-grown $\mathrm{CaI}_{2}: \mathrm{Eu}^{2+}$ crystal $(3 \% \mathrm{Eu}$, The material was melt frit filtered - but not vacuum-melt-pumped) and for a BGO reference standard - both excited by a $662 \mathrm{keV}$ gamma rays from a Cs-137 source.

Fig. 7. Pulse height spectra (662 keV gamma-ray excitation) for a 3\% Eu-doped $\mathrm{CaI}_{2}: \mathrm{Eu}^{2+}$ crystal that was frit filtered, but the melt was not treated by the extended vacuum melt pumping procedure described in Section 32.2 of the text. This crystal has a light yield of 50,800 photons/ $\mathrm{MeV}$ and an energy resolution of $8.9 \%$. This pulse height spectrum is to be compared to that of a $3 \%$ Eu-doped $\mathrm{CaI}_{2}: \mathrm{Eu}^{2+}$ crystal where the melt was frit filtered and then vacuum-melt-pumped for $48 \mathrm{~h}$. This extended vacuum-meltpumping resulted in a significant decrease in the light yield and the energy resolution as shown in the figure. This decrease is attributed to a loss of some amount of Eu-activator that occurs over time at the $\mathrm{CaI}_{2}$ melting point of $779^{\circ} \mathrm{C}$.

Fig. 8. Pulse height spectra are shown for the $3 \%$ Eu-doped Bridgman-grown $\mathrm{CaI}_{2}: \mathrm{Eu}^{2+}$ crystal shown in Fig. 7 that was frit filtered but not vacuum-melt-pumped. The light yield for this sample was 50,800 photons/MeV. The higher-light-yield spectrum (light yield $=54,900$ Photons $/ \mathrm{MeV})$ shown here was obtained for a $\mathrm{CaI}_{2}: \mathrm{Eu}^{2+}(2 \% \mathrm{Eu})$ crystal where the un-doped $\mathrm{CaI}_{2}$ was first frit filtered, vacuum-melt-pumped for $24 \mathrm{~h}$, and subjected to a vertical Bridgman growth pass. This un-doped $\mathrm{CaI}_{2}$ material was then reloaded into the apparatus illustrated in Figs. 2a,b, doped with the Eu activator, re-melted and frit filtered - but not subjected to an extended vacuum-melt-pumping step. The outer 
quartz envelope was then back-filled with 0.5 atm of pure Ar and sealed for a second slow Bridgman growth run. This two-stage procedure resulted in the growth of the highest quality single crystals produced in the present work (see the bottom photograph in Fig.3).

Fig. 9. Pulse height spectrum for a Bridgman-grown un-doped single crystal of $\mathrm{CaI}_{2}$ obtained using $662 \mathrm{keV}{ }^{137} \mathrm{Cs}$ gamma-ray excitation. The material was frit filtered but not subjected to the extended vacuum-melt-pumping procedure. The broad photopeak/poor energy resolution shown here is typical of the pure $\mathrm{CaI}_{2}$ spectra we have obtained - even though the light yield for this material was $\sim 40,000$ photons/MeV.

Fig. 10. Pulse height spectra for $5 \% \mathrm{Eu}$-doped Bridgman-grown $\mathrm{CaI}_{2}: \mathrm{Eu}^{2+}$ crystals excited by $662 \mathrm{keV}{ }^{137} \mathrm{Cs}$ gamma rays. The spectrum for the un-bent crystal has a photopeak that exhibits the multi-peak structure that is generally characteristic of samples with higher Eu doping levels. The spectrum for the same crystal that was plastically deformed by bending around a $5.0 \mathrm{~cm}$-diameter mandrel and then re-straightened on a flat plate has a photopeak that is significantly sharper and that has now moved to higher channel/light yield values. Accordingly, the act of bending and re-straightening the crystal has, in fact, improved the scintillation properties of the crystal - a result that is opposite to the originally anticipated behavior.

Fig. 11. The photopeaks are shown for one 5\% Eu-doped Bridgman-grown crystal of $\mathrm{CaI}_{2}: \mathrm{Eu}^{2+}$ that is as grown (i.e., un-bent) and that has then been repeatedly bent around the $5.0 \mathrm{~cm}$-diameter mandrel and then re-straightened the number of times indicated on the figure. These results show that the photopeak position moves to slightly higher channel umber after each cycle of bending and re-straightening. The mechanism responsible for this behavior and its implications for energy transfer processes in scintillation phenomena are not understood at this time.

Fig. 12. X-ray-excited (150 $\left.\mathrm{kV}_{\text {peak }}\right)$ luminescence spectra are shown for an as-grown (i.e., un-bent) single crystal of $5 \% \mathrm{Eu}$-doped $\mathrm{CaI}_{2}: \mathrm{Eu}^{2+}$ and for the same crystal after a series 
of three cycles of being bent and re-straightened. The shift in the peak position of the luminescence spectrum for the two cases is relatively small while alterations of the pulse height spectra are significant as illustrated in Figs. 10 and 11.

Fig. 13. Pulse height spectra are shown for an un-doped Bridgman-grown single crystal of $\mathrm{CaI}_{2}$ in the as-grown (unbent) state and after a single cycle of bending around a 5.0 $\mathrm{cm}$-diameter mandrel followed by re-straightening. The behavior of the un-doped crystal, in this case, is in accordance with the initially expected behavior (i.e. opposite to that observed for the Eu-doped material) in that here the photopeak broadens and shifts to low channel (light yield) values following plastic deformation. 


\section{$\mathrm{Cal}_{2}$}

- P-3m1

- $a=4.490 \mathrm{~A}$

- $c=6.975 \mathrm{~A}$

- $V=121.78 \mathrm{~A}^{3}$

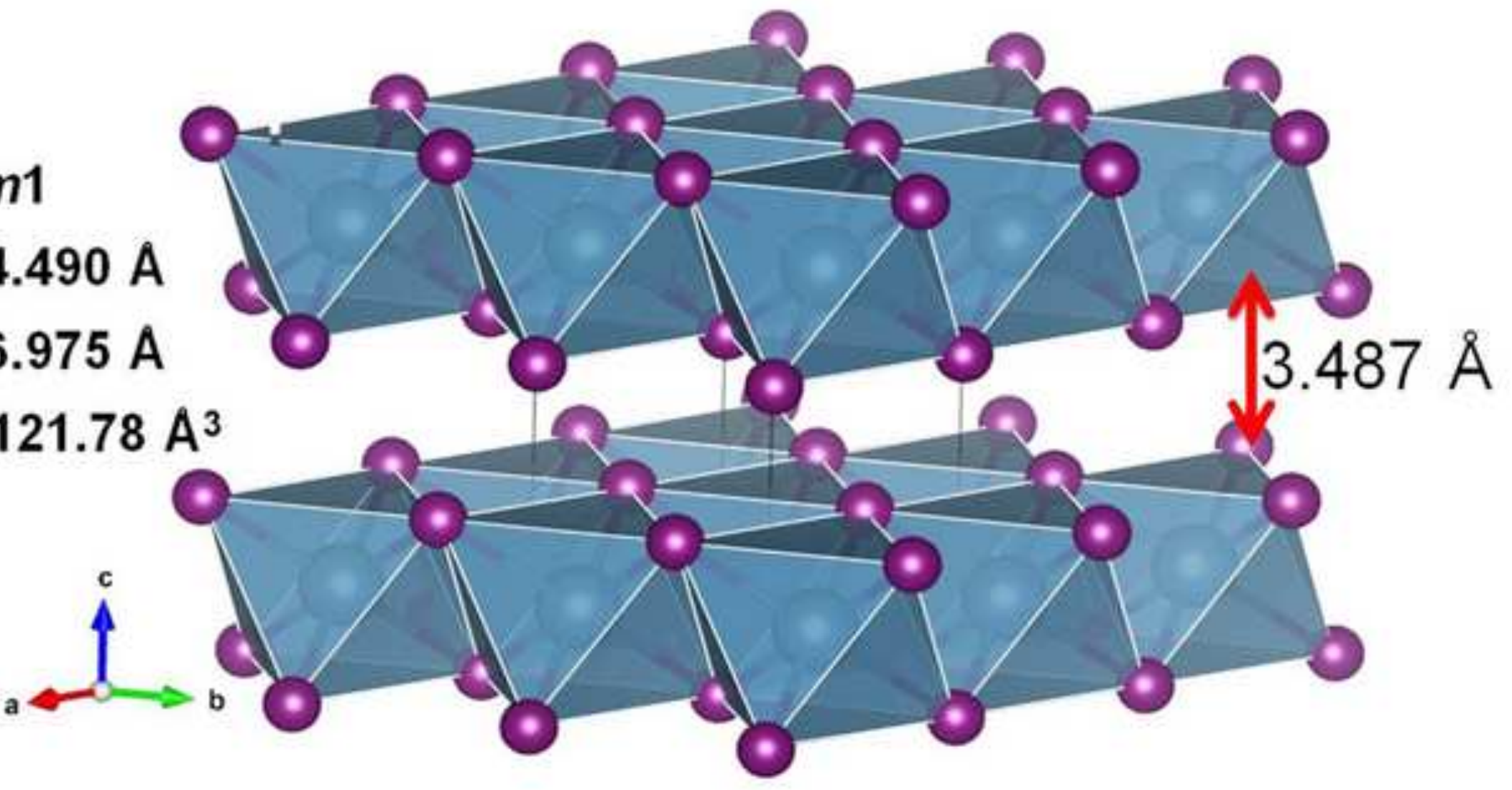

M. P. $=779^{\circ} \mathrm{C}$ 
Figure 2 - color
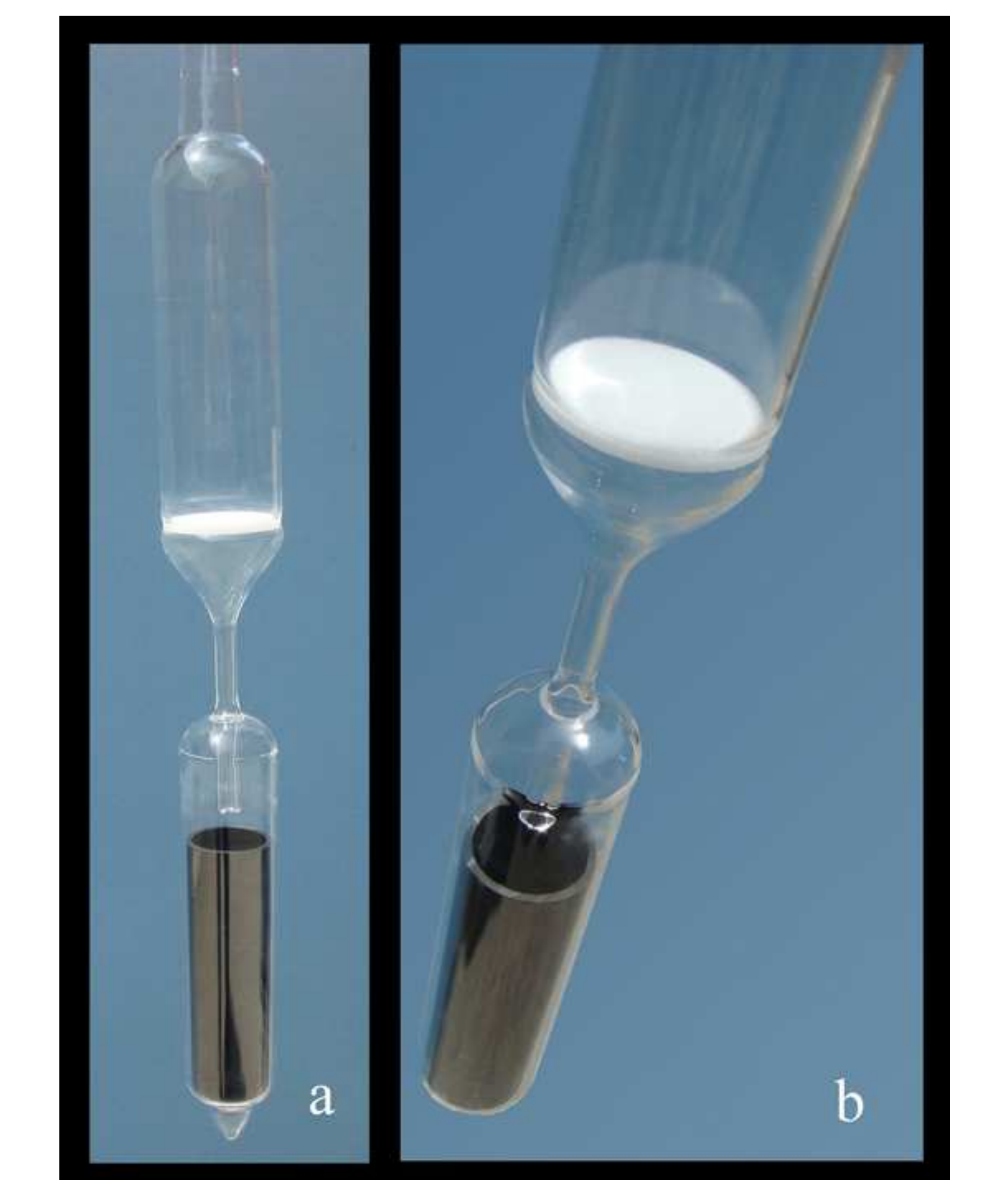

.

.

.

.

. 
Figure 3 - BW
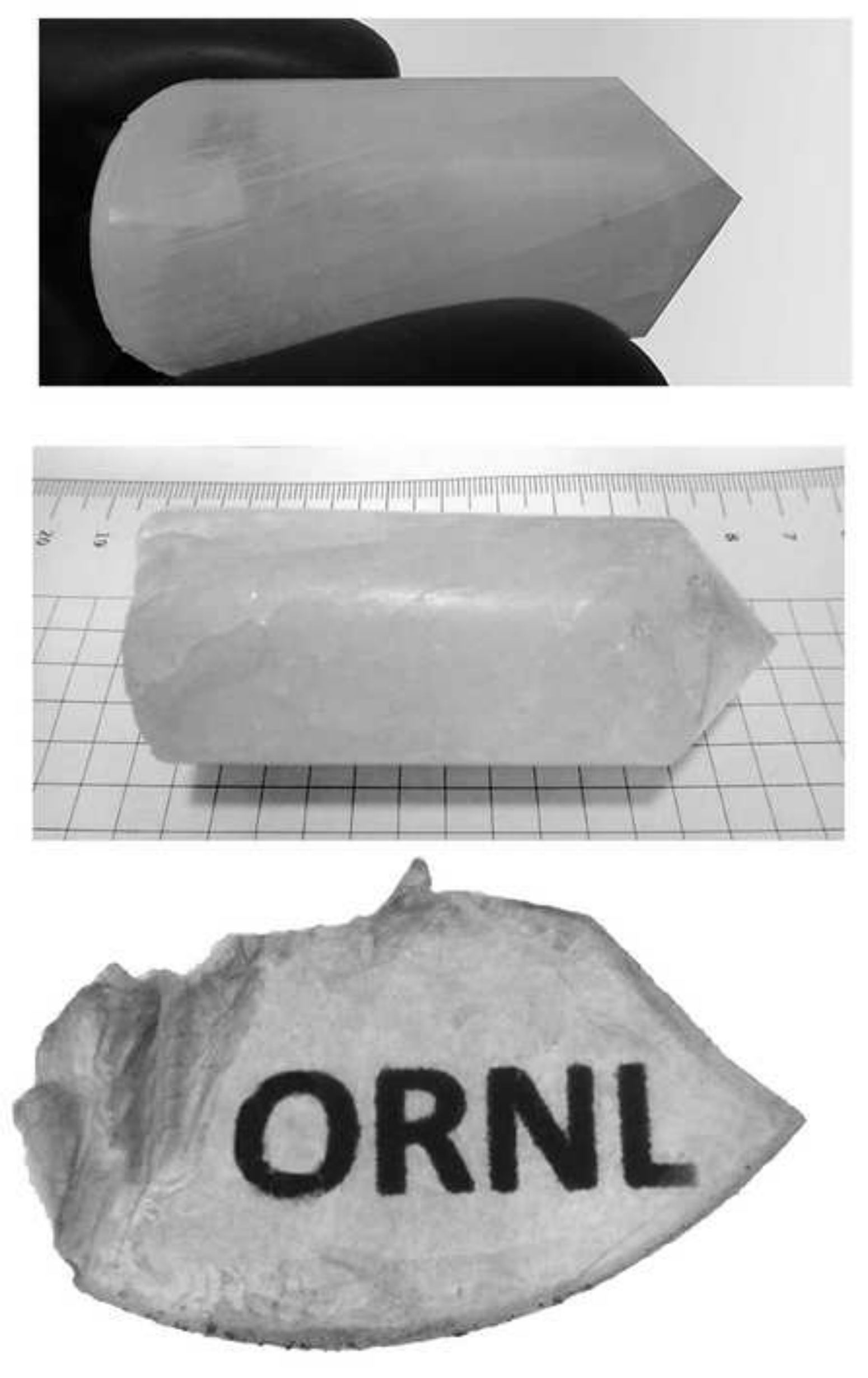

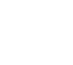
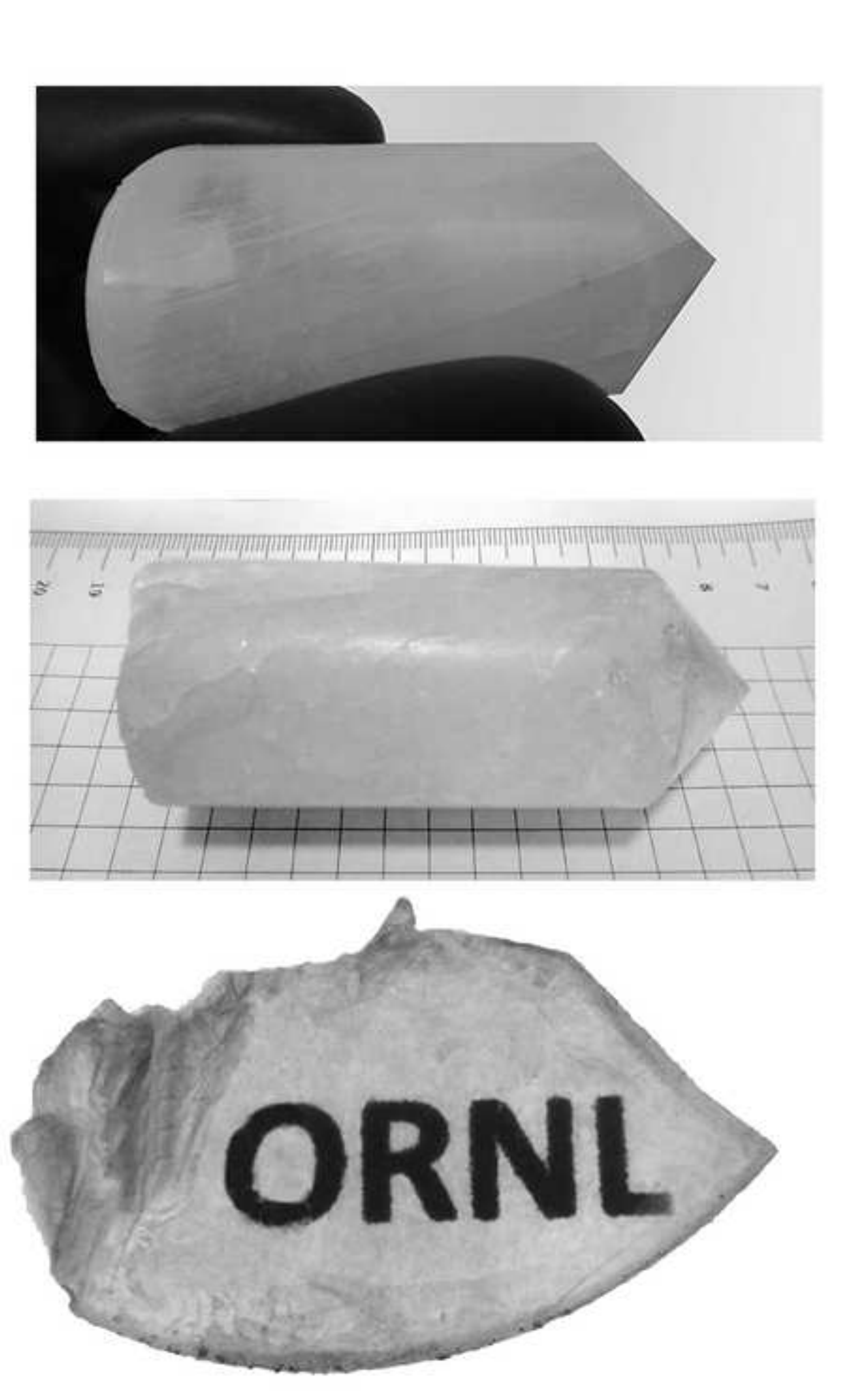

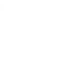
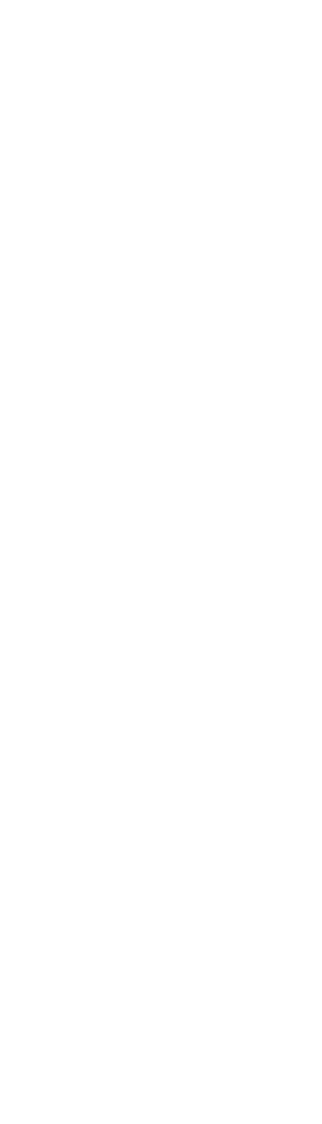


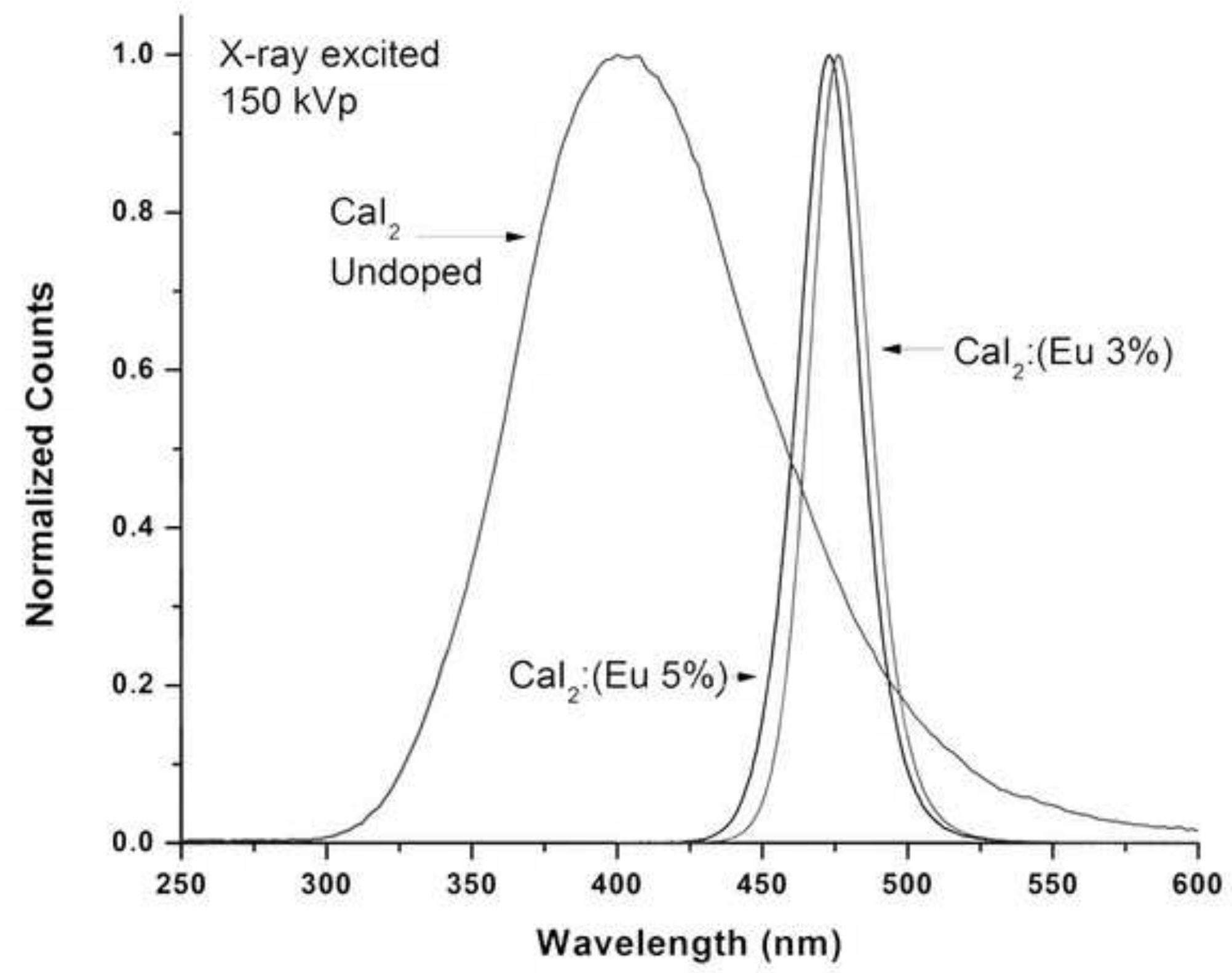




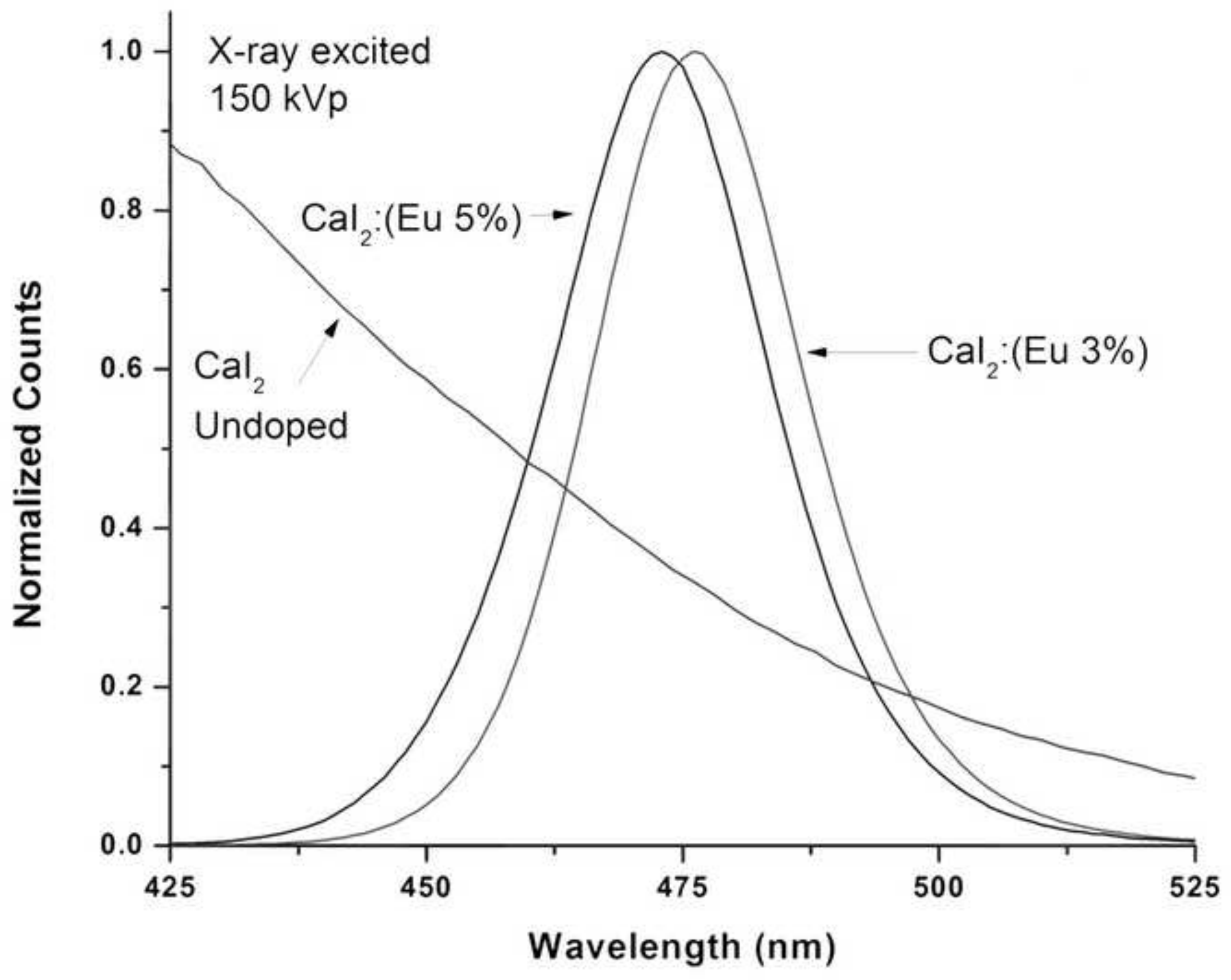




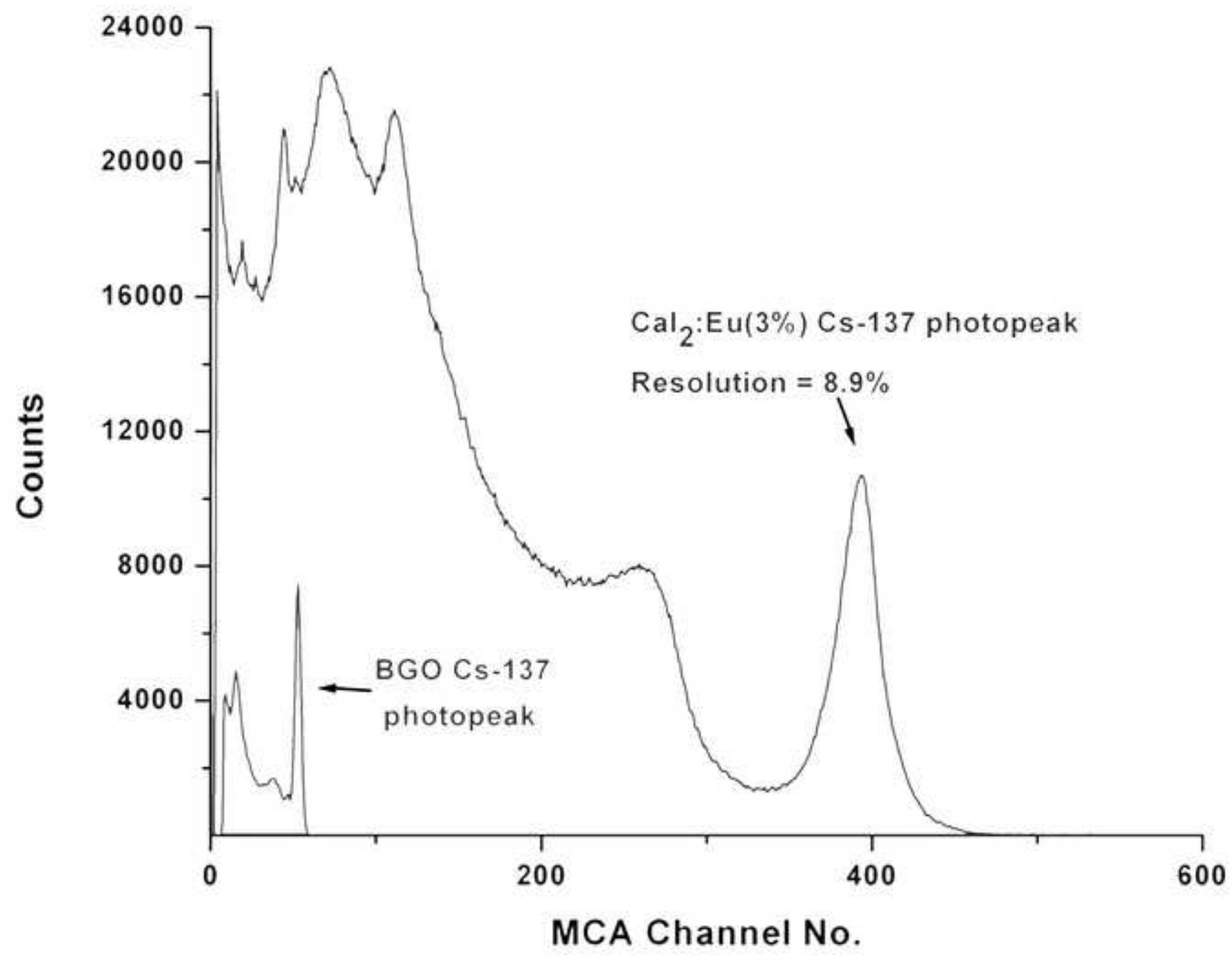




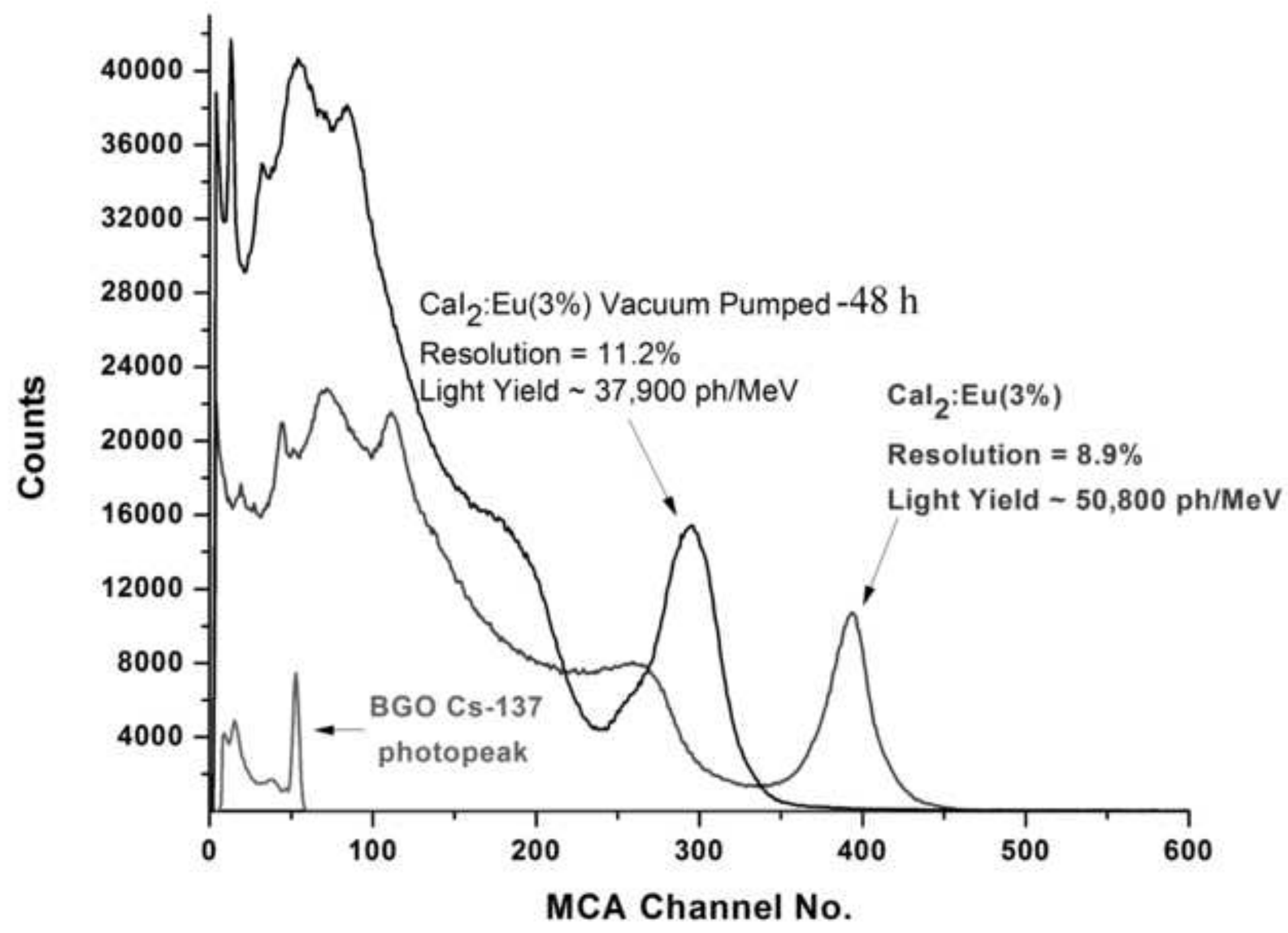




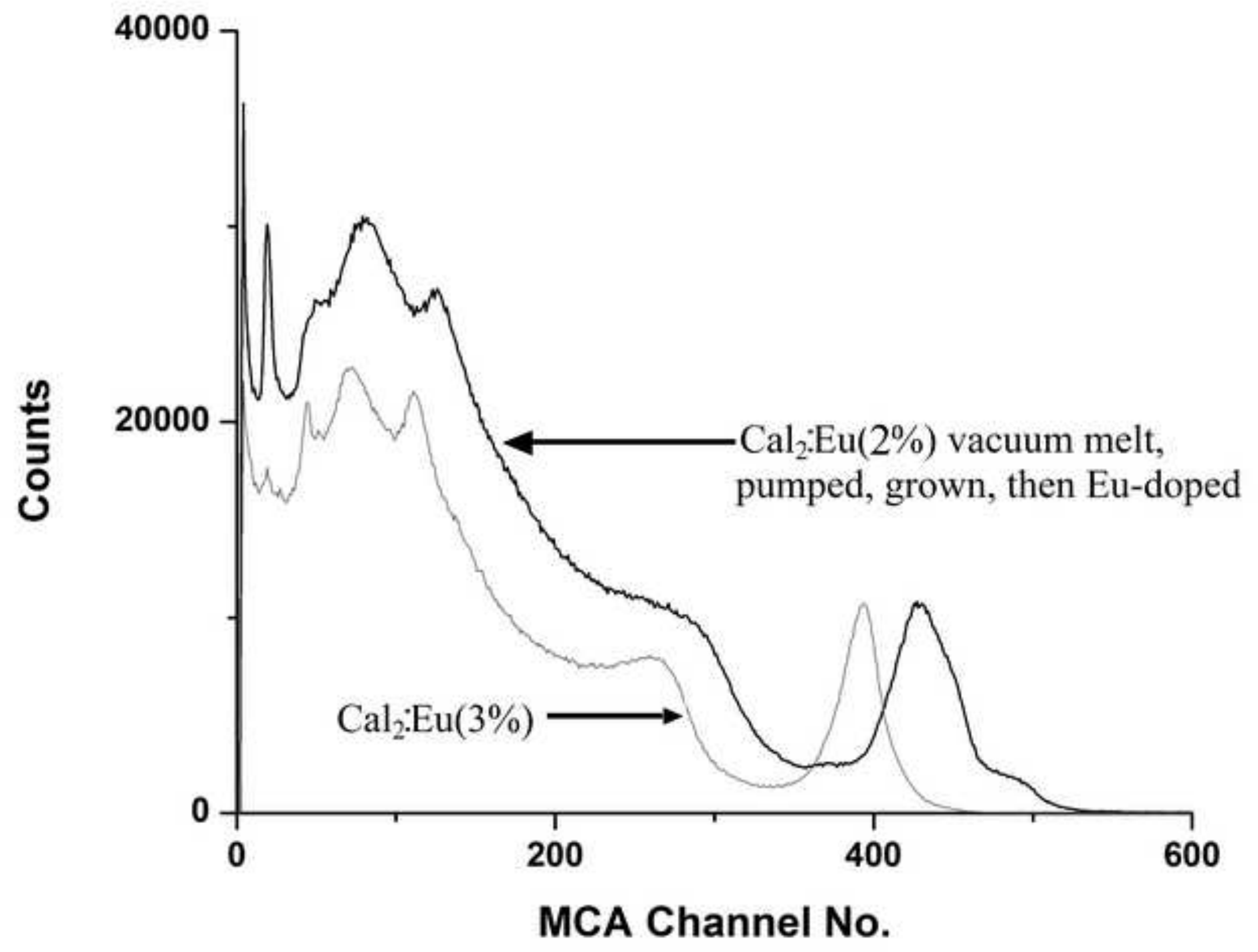




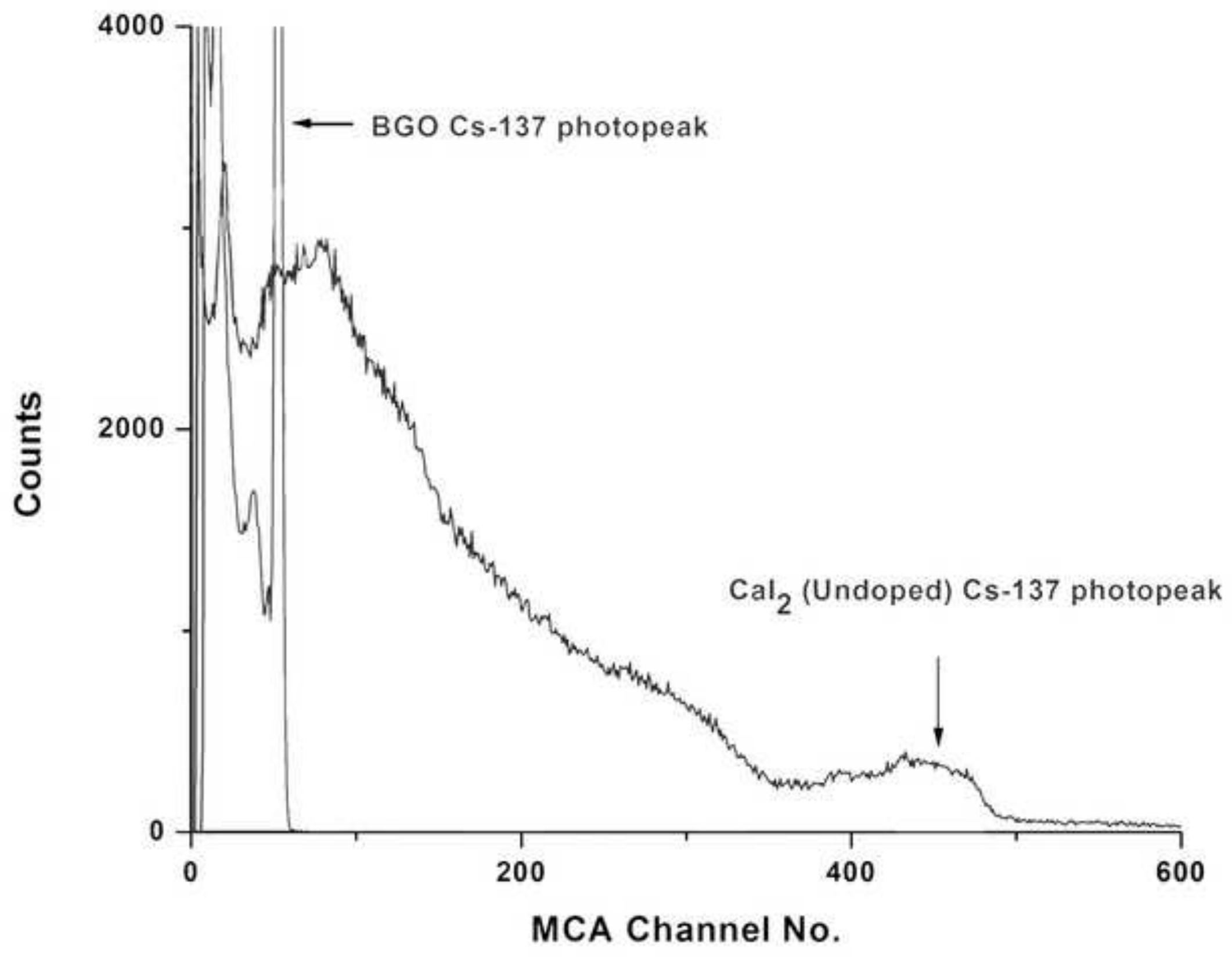




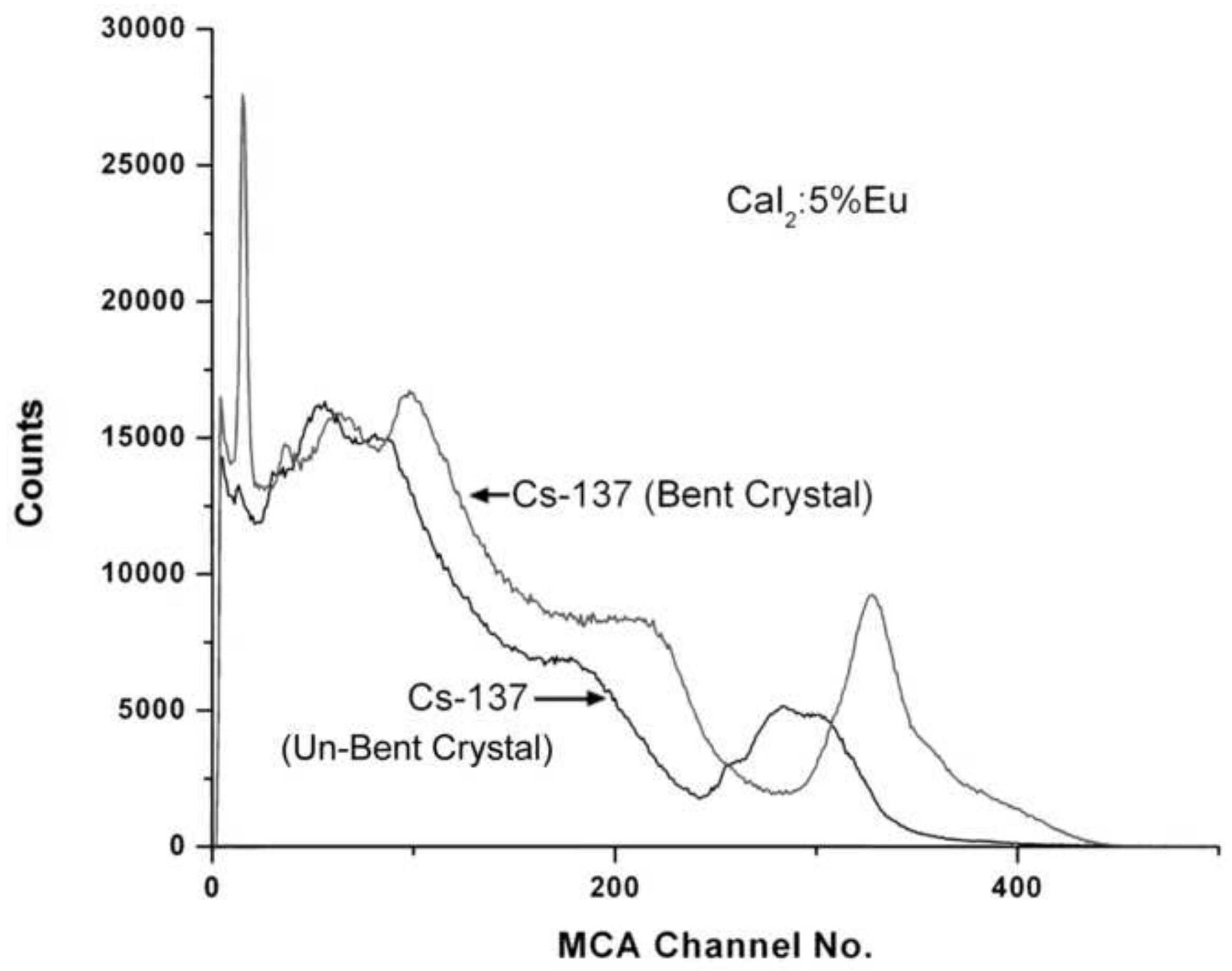




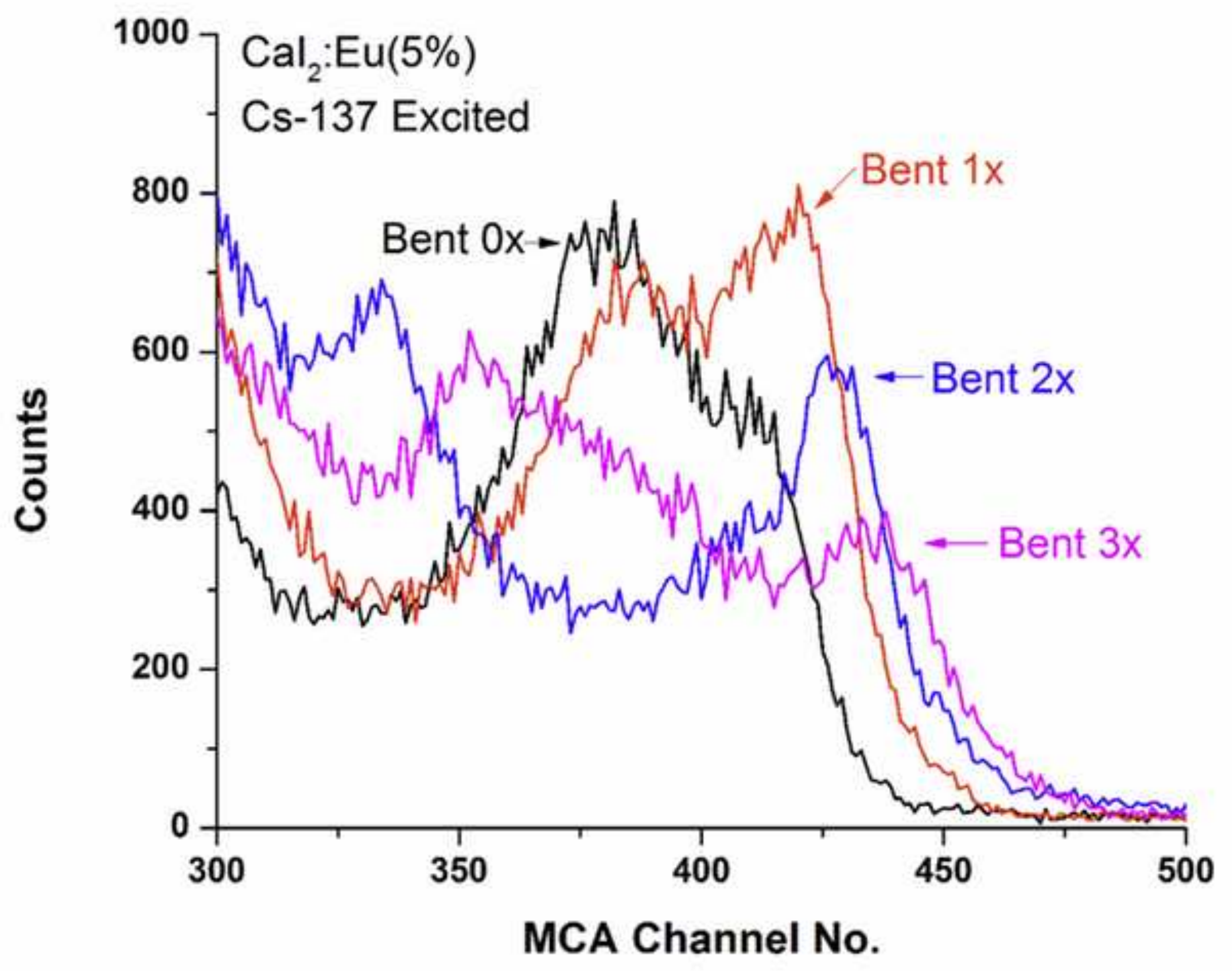




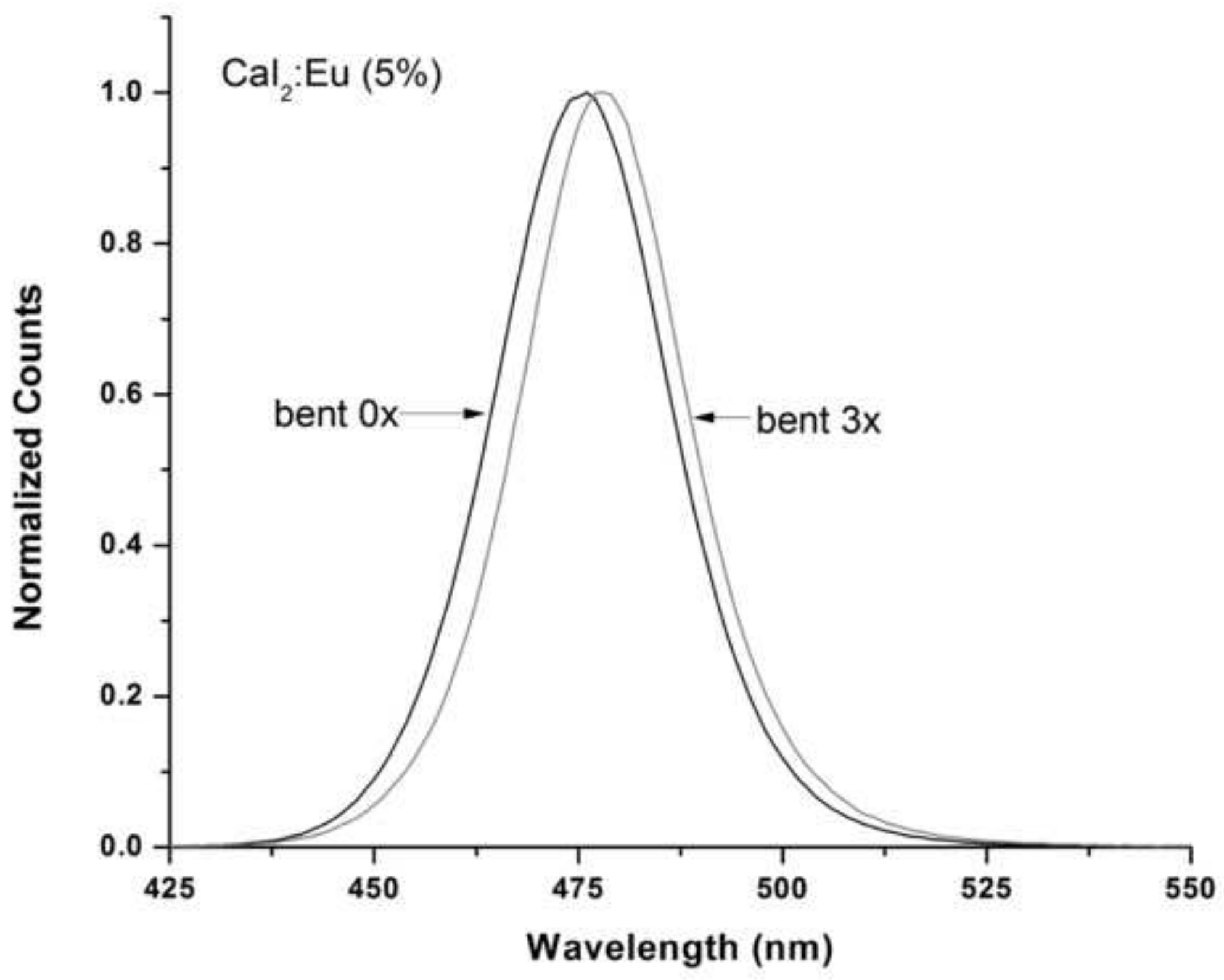




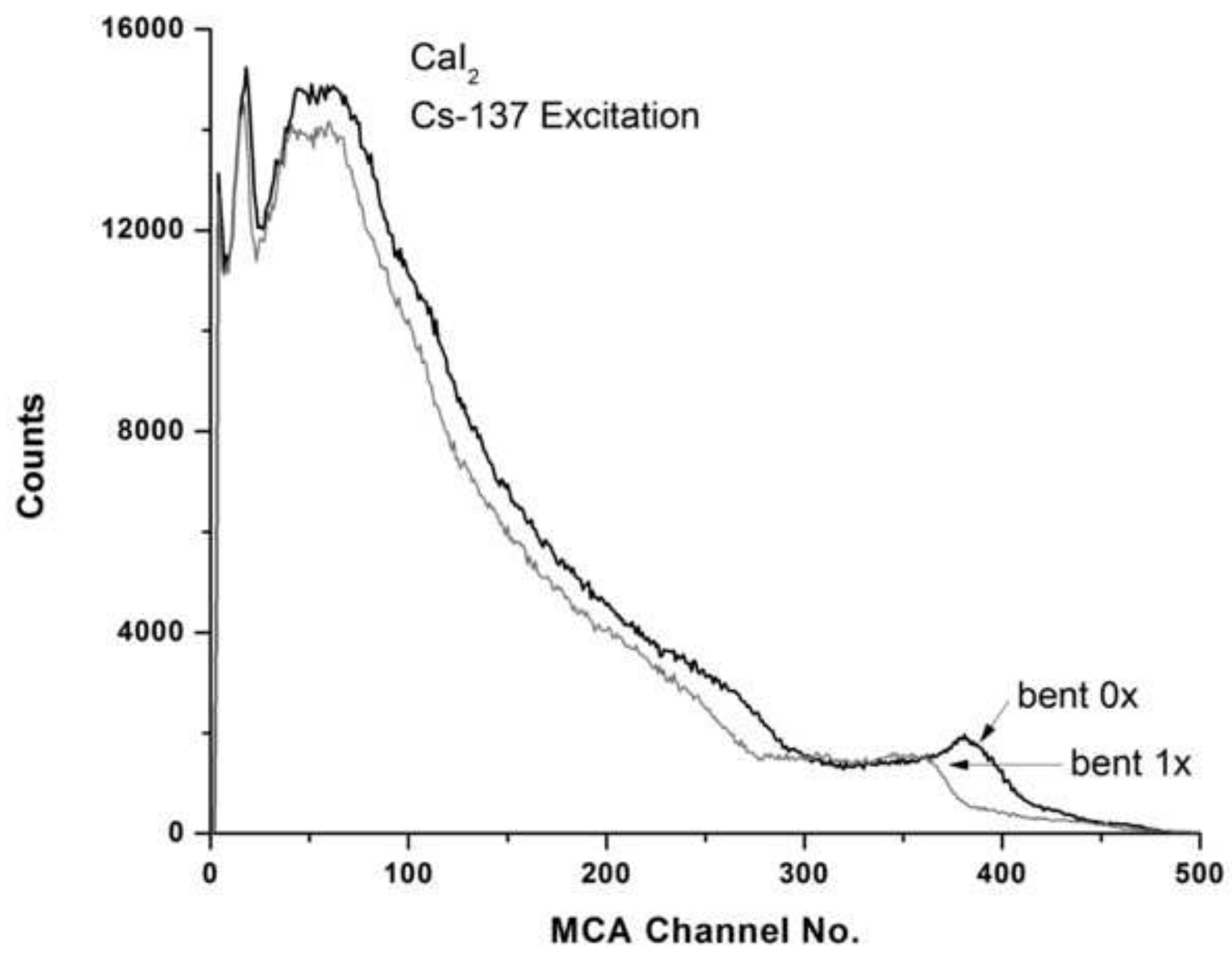

